\title{
cDNA cloning, expression and chromosomal localization of the human sarco/endoplasmic reticulum $\mathrm{Ca}^{2+}$-ATPase 3 gene
}

\author{
Leonard DODE $\$$, Frank WUYTACK*, Patrick F. J. KOOLS $+\ddagger$, Fouzia BABA-AISSA*, Luc RAEYMAEKERS*, Filip BRIK\$*, \\ Wim J. M. VAN DE VEN† and Rik CASTEELS* \\ *Laboratorium voor Fysiologie and †Centrum voor Menselijke Erfelijkheid en Vlaams Interuniversitair Instituut voor Biotechnologie, Katholieke Universiteit Leuven, \\ Campus Gasthuisberg, Herestraat 49, B-3000, Leuven, Belgium
}

\begin{abstract}
cDNA and genomic clones encoding human sarco/endoplasmic reticulum $\mathrm{Ca}^{2+}$-ATPase 3 (SERCA3) were isolated. The composite nucleotide sequence of the $4.6 \mathrm{~kb}$ cDNA, as well as the partial structure of $25 \mathrm{~kb}$ of genomic DNA encoding all but the $5^{\prime}$ region of the gene, was determined. The nucleotide sequence coding for the last six amino acids of the pump and the 3'untranslated region were identified within the sequence of the last exon. Northern blot hybridization analysis using cDNA probes derived from this exon detected a $4.8 \mathrm{~kb}$ transcript in several human tissues. Using a cDNA probe derived from the $5^{\prime}$ coding region an unexpected mRNA distribution pattern, consisting of two mRNA species of 4.8 and $4.0 \mathrm{~kb}$, was detected in thyroid gland and bone marrow only. This is the first indication of an alternative splicing mechanism operating on the SERCA3 gene transcript, which most likely generates SERCA3 isoforms
\end{abstract}

with altered C-termini. Human SERCA3 expressed in platelets and in COS cells transfected with the corresponding cDNA was detected with the previously described antibody N89 (directed against the N-terminal region of rat SERCA3) and with a new SERCA3-specific antiserum C91, directed against the extreme C-terminus of the human isoform. A monoclonal antibody $\mathrm{PL} / \mathrm{IM} 430$, previously assumed to recognize SERCA3 in human platelets, does not react with the $97 \mathrm{kDa}$ human SERCA3 transiently expressed in COS cells. Therefore the $97 \mathrm{kDa}$ isoform detected by PL/IM430 more likely represents a novel SERCA pump, as recently suggested [Kovács, Corvazier, Papp, Magnier, Bredoux, Enyedi, Sarkadi and Enouf (1994) J. Biol. Chem. 269, 6177-6184]. Finally, by fluorescence in situ hybridization and chromosome G-banding analyses, the SERCA3 gene was assigned to human chromosome 17p13.3.

\section{INTRODUCTION}

Sarco/endoplasmic reticulum $\mathrm{Ca}^{2+}$-ATPases (SERCAs) are membrane-spanning proteins catalysing the active transport of $\mathrm{Ca}^{2+}$ across membranes bordering $\mathrm{Ca}^{2+}$-sequestering stores such as the sarcoplasmic or endoplasmic reticulum [1]. In higher vertebrates, the $\mathrm{Ca}^{2+}$ pumps of the SERCA family are encoded by at least three distinct genes, SERCA1-3. Further isoform diversity is brought about by alternative processing of the primary gene transcripts in a developmentally modulated or tissue-specific manner [2]. SERCA1 is exclusively expressed in adult and neonatal fast-twitch skeletal muscles, giving rise to the alternatively spliced isoforms SERCA1a and SERCA1b respectively [3-6]. Tissue-dependent processing of the primary transcript of the SERCA2 gene results in the expression of the SERCA2a protein in cardiac and slow-twitch muscles and of the SERCA2b isoform in smooth muscle and most non-muscle tissues [7-10]. For both genes, alternative splicing affects the region encoding their C-termini.

SERCA3 cDNA was first cloned from rat kidney [11]. Its tissue-specific expression pattern remained poorly understood until recently. SERCA3 is always co-expressed along with the housekeeping isoform SERCA2b (for a recent review on
SERCA3, see [12]). Recent studies demonstrated high expression levels of SERCA3 in cells of the haematopoietic cell lineage and related cells such as platelets, lymphoid and mast cells [13,14], but also in the embryologically related endothelial cells [15]. It has been suggested that SERCA3 expression also occurs in trachea and intestine, where it would be restricted to the secretory epithelial cells [15,16], and in the Purkinje neurons of the cerebellum [16,17]. SERCA3 presents, upon expression in COS cells, some peculiar functional properties : a 5-fold lower apparent affinity for $\mathrm{Ca}^{2+}$, an altered $\mathrm{pH}$ optimum ( $\mathrm{pH} 7.2-7.4$ versus $\mathrm{pH}$ 6.8-7.0) and a 10-fold higher apparent affinity for vanadate inhibition when compared with the other members of the SERCA family [18].

We recently documented SERCA3 expression at the protein level in both human and rat platelets [13] by using two new antiSERCA3 specific antisera, N89 and C90, directed respectively against the $\mathrm{N}$ - and $\mathrm{C}$-terminal parts of rat SERCA3. Whereas N89 recognized the isoforms in both species, C90 failed to detect the human pump. Additionally, a monoclonal antibody PL/IM430 raised against human platelet intracellular membranes and known to inhibit $\mathrm{Ca}^{2+}$ uptake in platelet microsomes [19] was also reported to bind human but not rat SERCA3 $[13,20]$. Other data indicate that PL/IM430 binds to a putative

Abbreviations used: CIRATP, $\gamma$-[4-(N-2-chloroethyl-N-methylamino)]benzylamide ATP; FISH, fluorescence in situ hybridization; FITC, fluorescein isothiocyanate; FSBA, 5'-p-fluorosulphonylbenzoyladenosine; SERCA, sarco/endoplasmic reticulum Ca ${ }^{2+}$-ATPase.

* Current address: Laboratory for Molecular Cell Biology, Section of Molecular Biology, and Flanders Institute for Biotechnology, University of Gent, K. L. Ledeganckstraat 35, B-9000 Gent, Belgium.

$\S$ To whom correspondence and reprint requests should be addressed

The nucleotide sequence data reported in this paper have been deposited in the EMBL/GenBank/DDBJ Nucleotide Sequence Databases under accession nos. Z69880 and Z69881. 
novel member of the SERCA family, which presents a similar apparent molecular mass (97 kDa) as SERCA3 [21]. Unlike for SERCA1 and SERCA2, Northern blot analysis [11,16] has revealed the presence of only one transcript of $4.8 \mathrm{~kb}$ for SERCA3 in a broad variety of rat tissues examined so far.

Although the only known SERCA3 sequence information was deduced from the rat cDNA, most of the studies at the protein level have been done on human cells, especially platelets. In order to further elucidate the expression pattern of the human SERCA3 pump, we have determined its corresponding cDNA sequence. Moreover, genomic clones have been isolated and the structure of the $3^{\prime}$-end of the gene and its chromosomal localization are reported. In addition, we present evidence for alternative splicing of the SERCA3 primary transcript in some tissues and confirm indirectly the existence of another $97 \mathrm{kDa}$ SERCA-related $\mathrm{Ca}^{2+}$ pump.

\section{EXPERIMENTAL}

\section{Materials and chemicals}

Restriction endonucleases, T4 ligase, T4 polynucleotide kinase and broad-range protein markers were supplied by New England Biolabs, Beverly, MA, U.S.A. The Expand ${ }^{\mathbb{R}}$ LD PCR kit, which uses a mixture of Taq and Pwo polymerases, was from Boehringer Mannheim, Brussels, Belgium. Unless otherwise stated, all cDNA probes were labelled using a Boehringer kit, based on random hexanucleotide priming [22]. $\left[\alpha^{-32} \mathrm{P}\right] \mathrm{dCTP}(6000 \mathrm{Ci} / \mathrm{mmol}),[\gamma-$ $\left.{ }^{32} \mathrm{P}\right] \mathrm{ATP}(800 \mathrm{Ci} / \mathrm{mmol})$ and Hybond-N nylon membranes were from Amersham International, Little Chalfont, Bucks., U.K. Sephadex G-50 columns for probe purification were purchased from Pharmacia LKB Biotech Benelux, Roosendaal, The Netherlands, as were the AutoRead ${ }^{\circledR}$ Sequencing kit and the FluorodATP Labeling Mix. Plasmid, phage and cosmid DNA preparations were carried out using QIAGEN kits (Qiagen, Hilden, Germany). Restriction fragments used for either probe synthesis or subcloning procedures were gel-purified using the QIAEX II Gel Extraction kit (Qiagen). pBluescript ${ }^{\mathrm{R}} \mathrm{SK}(-)$ vector (Stratagene, La Jolla, CA, U.S.A.) was chosen for all subcloning steps. Sets of overlapping DNA clones were generated by exonuclease III/S1 nuclease (Erase-a-base kit; Promega, Madison, WI, U.S.A.). Gene-specific oligonucleotides and fluorescein-labelled sequencing primers were from Pharmacia. Immobilon-P transfer membranes (Millipore, Brussels, Belgium) were used for Western blotting. The secondary antibodies were peroxidase-conjugated swine anti-rabbit or peroxidase-conjugated rabbit anti-mouse immunoglobulins (DAKO A/S, Glostrup, Denmark). GibcoBRL Life Technologies (Merelbeke, Belgium) supplied cell culture reagents and various chemicals. Other molecular biology grade chemical compounds were purchased from Sigma (St. Louis, MI, U.S.A.), Merck and Pharmacia.

\section{Preparation and labelling of a human SERCA3 CDNA probe}

A 190 bp probe was generated by PCR using as template a plasmid DNA containing a previously characterized $209 \mathrm{bp}$ fragment of human SERCA3 [13]. The $5^{\prime}$ primer was the same as in [13] (5'-TGCCTGGTAGAGAAGATGAA-3'), corresponding to nucleotides 1470-1489 in the rat sequence (numbering according to sequence of EMBL/GenBank data accession no. J05086) and to nucleotides 1339-1358 in the human sequence (present paper, Figure 2); note, however, that our sequencing indicated that the underlined base (A) of the rat is replaced by a $\mathrm{G}$ in the human sequence. The new $3^{\prime}$ primer (5'-CCTGGCCGGTAGGGTGAGGGCGGGTG-3') corresponds to the inverse complement of nucleotides 1500-1525 in human SERCA3 (Fig- ure 2). Amplification was carried out in the presence of $50 \mu \mathrm{Ci}$ of $\left[\alpha{ }^{32} \mathrm{P}\right] \mathrm{dCTP}$ and Taq and Pwo polymerases for 20 cycles, each cycle consisting of $30 \mathrm{~s}$ of denaturation at $94^{\circ} \mathrm{C}, 30 \mathrm{~s}$ of annealing at $58^{\circ} \mathrm{C}$ and $30 \mathrm{~s}$ of extension at $72{ }^{\circ} \mathrm{C}$.

\section{Isolation and characterization of cDNA clones}

A human T-cell (Jurkat) oligo(dT)-primed cDNA library constructed in the EcoRI cloning site of $\lambda$ ZAP-II vector was purchased from Stratagene, and $1 \times 10^{6}$ independent plaqueforming units were plated. Duplicate replica filters were initially screened with the human $190 \mathrm{bp}$ cDNA. Hybridization of the filters was always carried out overnight at $42{ }^{\circ} \mathrm{C}$ in $2 \times$ Pipes buffer (0.02 M Pipes, $0.8 \mathrm{M} \mathrm{NaCl}, \mathrm{pH} 6.5), 0.5 \%$ SDS, $50 \%$ formamide, $100 \mu \mathrm{g} / \mathrm{ml}$ denatured salmon sperm DNA and $2 \times 10^{6}$ c.p.m. $/ \mathrm{ml}$ probe. Filters were washed three times for 30 min each in $0.1 \times \mathrm{SSC} / 0.1 \% \mathrm{SDS}$ at $65^{\circ} \mathrm{C}$. Four recombinant pBluescript plasmid clones designated $\mathrm{Z} 1, \mathrm{Z} 3, \mathrm{Z} 4$ and $\mathrm{Z} 8$ were obtained. Additional clones Z9, Z10 and Z17 were isolated when the library was rescreened with the $1.8 \mathrm{~kb} E c o$ RI insert of clone $\mathrm{Z} 3$ as probe. Clone Z21 was obtained using a 444 bp PstI-Eco RI restriction fragment, representing the $3^{\prime}$-end of clone Z17. A K562 cell line cDNA library constructed in the $\lambda$ gt11 vector and purchased from Clontech (Palo Alto, CA, U.S.A.) was screened with an EcoRI-BamHI fragment (5'-end of clone Z8) as probe according to the manufacturer's instructions (Clontech). Three positives (clones $\mathrm{K} 1, \mathrm{~K} 2$ and $\mathrm{K} 3$ ) were plaque-purified, the inserts excised by EcoRI digestion and subcloned in pBluescript vector.

The composite human SERCA3 cDNA nucleotide sequence (accession no. Z69881) in both strands was determined using the Automated Laser Fluorescent A.L.F. ${ }^{\circledR}$ DNA Sequencer from Pharmacia. The sequencing strategy is shown in Figure 1.

\section{Isolation and characterization of genomic clones}

A total of 250000 clones from a human genomic library CMLW25383 [23], constructed in pJB8 cosmid vector, were screened with a 3353 bp Not I-BglII fragment of the rat SERCA3 cDNA clone RK 8-13 (a gift from Dr. G. E. Shull, University of Cincinnati, OH, U.S.A.) as probe. At that stage, human SERCA3 cDNA clones were not yet available. The NotI-BglII fragment comprised $86 \mathrm{bp}$ of the $5^{\prime}$-untranslated region, the entire coding sequence and $122 \mathrm{bp}$ of the $3^{\prime}$-untranslated region.

Hybridization of the filters was carried out for $16 \mathrm{~h}$ at $42{ }^{\circ} \mathrm{C}$ in $5 \times$ SSPE, $50 \%$ formamide, $5 \times$ Denhardt's solution, $5 \mathrm{mg} / \mathrm{ml}$ denatured salmon sperm DNA and $10^{6}$ c.p.m. $/ \mathrm{ml}{ }^{32} \mathrm{P}$-labelled probe, followed by two washes of $30 \mathrm{~min}$ each in $1 \times \mathrm{SSC} / 1 \%$ SDS at $65^{\circ} \mathrm{C}$ and one wash of $30 \mathrm{~min}$ in $1 \times \mathrm{SSC}$ at $65^{\circ} \mathrm{C}$. One positive clone (GHS3) was isolated and further characterized. Cosmid DNA was digested using EcoRI, HindIII, NotI, ClaI and various combinations of these enzymes, size-fractionated by $0.7 \%$ agarose-gel electrophoresis, transferred to Hybond-N membranes and analysed by Southern blot hybridization. The probes used were the entire NotI-BglII fragment and two fragments derived from it: a 390 bp NotI-PvuI fragment (as 5'end probe) and a $743 \mathrm{bp}$ SnaBI-BglII fragment (as $3^{\prime}$-end probe). All positive restriction fragments were subcloned. Sets of PCR primers were designed from the human cDNA sequence and used to determine the size of introns and the sequence around exon/intron junctions.

\section{Construction and expression of cDNA in COS-1 cells}

A full-length composite clone (pHS3) was constructed from the overlapping clones Z1, Z8, Z10 and Z17, using the BamHI, SphI 


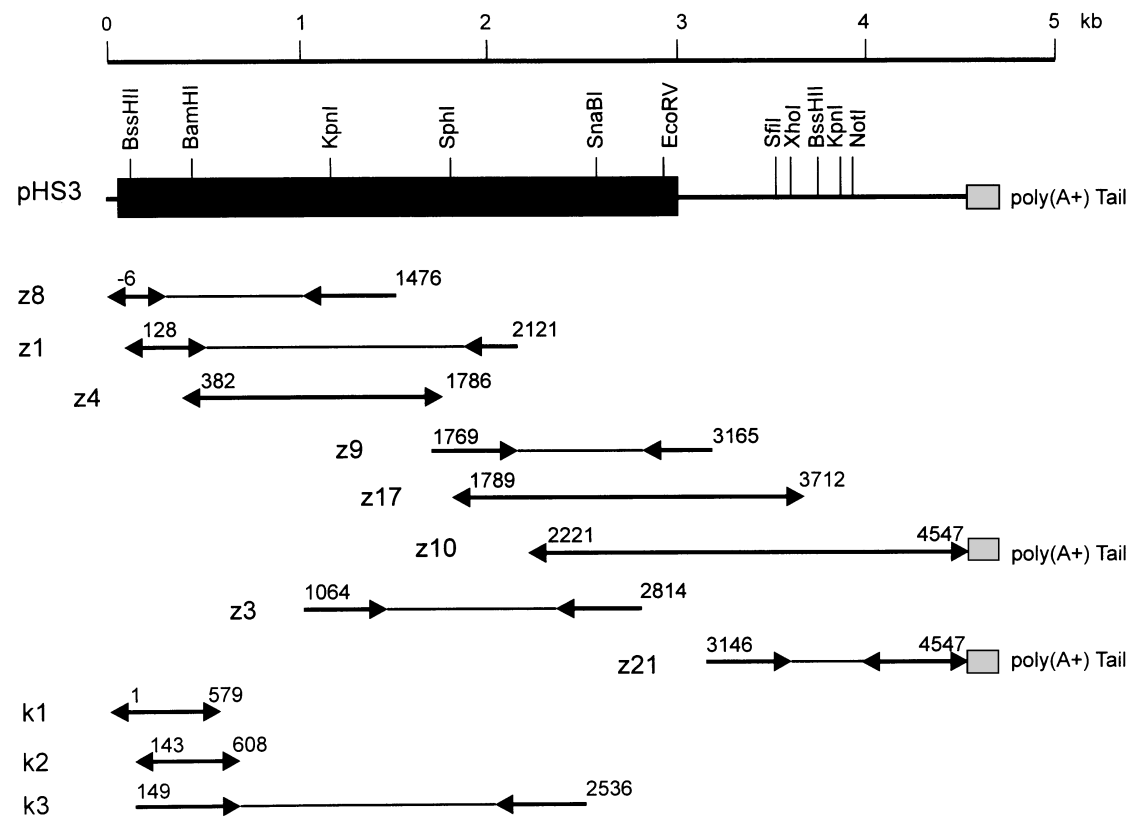

Figure 1 Restriction map and sequencing strategy for the human SERCA3 cDNA clones

The full-length composite clone pHS3 is shown below the scale line. A black box represents the open reading frame and the flanking lines represent the untranslated sequences. Grey boxes denote the poly $(A)^{+}$tail. The overlapping $Z$ and $\mathrm{K}$ clones, isolated from Jurkat and $\mathrm{K} 562$ libraries respectively, are shown beneath the restriction map and are numbered relative to the translation initiation site. The Z1, Z8, Z10 and Z17 clones were used to construct the pHS3 clone. The composite nucleotide sequence shown in Figure 2 was compiled from the overlapping Z clones. For each clone, heavy lines and arrows indicate the extent and direction of sequencing. Single or double arrowheads denote that sequencing was done in one or both strands respectively.

and $X$ hoI restriction sites. The pHS3 cDNA was excised with EcoRI and transferred into an EcoRI-cut and dephosphorylated mammalian expression vector pMT2 (from R. J. Kaufmann, Genetics Institute, Boston, MA, U.S.A.). COS-1 cell culture and DEAE-dextran-mediated DNA transfection were performed as described earlier [24].

\section{Membrane preparations and protein determination}

Platelet membrane vesicles were isolated from human, rat, cat and pig platelet-rich plasma as previously described [25]. Microsomes were isolated from COS- 1 cells expressing rat SERCA3 according to Verboomen et al. [24]. Besides the microsomal pellet, the $1000 \mathrm{~g}$ nuclear pellet, which still contains a considerable amount of intracellular membranes, was kept for further analysis. Protein concentration was determined by the bicinchoninic acid method (Pierce, Rockford, IL, U.S.A.), using BSA as standard.

\section{Preparation of antibodies and immunoblotting analysis}

A synthetic peptide C91 (SRNHMHEEMSQK), corresponding to the extreme C-terminus of human SERCA3, was conjugated by means of glutaraldehyde to bovine thyroglobulin at a concentration of $0.17 \mathrm{mg}$ of peptide/mg of carrier, and antibodies were raised in rabbits against the conjugate as described earlier [13]. Preparation of the N89 and C90 anti-SERCA3 antibodies has been described previously [13]. The PL/IM430 monoclonal antibody (a gift from Dr. K. S. Authi, Thrombosis Research Institute, London, U.K.), initially raised against highly purified platelet intracellular membranes [19], recognizes a $97 \mathrm{kDa} \mathrm{Ca}^{2+}$ ATPase in platelets and in some other human cell types [21]. Denaturing-gel electrophoresis on $0.75-\mathrm{mm}$-thick $7.5 \%$ polyacrylamide slab gels, semi-dry blotting on to Immobilon-P membranes and immunostaining of the blots were done as reported earlier [13].

\section{Northern blot hybridization analysis}

Two human multiple-tissue Northern blots (Human MTN I and III blots) of high quality poly $\left(\mathrm{A}^{+}\right) \mathrm{RNA}$ were purchased from Clontech. These blots had been made by running $2 \mu \mathrm{g}$ of poly $(\mathrm{A})^{+}$ RNA from each specified tissue on a denaturing formaldehyde/ $1.2 \%$ agarose gel followed by transfer on to positively charged nylon membranes. We prepared a third Northern blot in the same way, using poly(A) ${ }^{+}$RNA from Jurkat and K562 cells and from human colon mucosa. Polyadenylated RNA was prepared from both Jurkat and K562 cells using the Micro-FastTrack kit (Invitrogen Co., British Biotechnology Products Ltd., Abingdon, U.K.). Total RNA was first isolated from human colon mucosa using the guanidinium isothiocyanate/ $\mathrm{CsCl}$ purification method [26], and poly(A) ${ }^{+}$RNA was then purified by oligo(dT)-cellulose column chromatography (Pharmacia). Membranes were hybridized by following the manufacturer's protocol (Clontech) and washed two times for $30 \mathrm{~min}$ each in $2 \times \mathrm{SSC} / 0.05 \%$ SDS at room temperature and two times for $30 \mathrm{~min}$ each in $0.1 \times$ SSC $/ 0.1 \%$ SDS at $60{ }^{\circ} \mathrm{C}$. DNA fragments to be used as hybridization probes were produced and ${ }^{32} \mathrm{P}$-labelled by PCR amplification using SERCA3 cDNA clone pHS3 as template DNA and a mixture of Taq and Pwo DNA polymerases. A human SERCA3 $5^{\prime}$-end cDNA probe was synthesized using the following pair of primers: a $5^{\prime}$ primer, NEP + (5'-ATCTGCTCCCGGCCGCCGACG-3'), corresponding to nucleotides 14-34, and a $3^{\prime}$ primer, PII (5'-AAAGGAGACAAGGGCAGCCAGCAGCA-3'), corresponding to the inverse complement of the nucleotide stretch 194-219. Similarly, a set of primers, $1(+)\left(5^{\prime}\right.$-GTGTGTACCTCAGACTGATGG-3') and 
31(-) (5'-CAAGTGAACGTCCAGCTTCC-3'), corresponding to nucleotides 3027-3047 and the inverse complement of nucleotides 3380-3399 respectively, was used to generate a 3 '-end probe (numbering according to the nucleotide sequence of human SERCA3 shown in Figure 2). PCR amplifications were carried out for 20 cycles, each cycle consisting of $30 \mathrm{~s}$ of denaturation at $94{ }^{\circ} \mathrm{C}, 30 \mathrm{~s}$ of annealing at $60^{\circ} \mathrm{C}$ for the $\mathrm{NEP}+/$ PII pair or at $57^{\circ} \mathrm{C}$ for the $1(+) / 31(-)$ pair, and $30 \mathrm{~s}$ of extension at $72{ }^{\circ} \mathrm{C}$.

\section{Fluorescence in situ hybridization (FISH) analysis}

Phytohaemagglutinin-stimulated peripheral blood lymphocytes from a normal male were used to prepare metaphase spreads according to established methods. FISH was performed according to Kievits et al. [27], using the biotin-11-dUTP labelled DNA of clone GHS3 as probe. Results were evaluated on a Zeiss Axiophot fluorescence microscope and recorded on Scotch (3M) ASA 640 film. Chromosome banding was carried out using a modified Wright's staining method [28].

\section{RESULTS}

\section{Isolation and characterization of cDNA clones coding for human SERCA3}

Since previous reverse transcriptase-PCR measurements indicated the expression of nearly equal levels of human SERCA3 and SERCA2 mRNAs in, amongst other cell types, K562 cells, lymphocytes and several T-cell lines [11,12], we decided to clone SERCA3 from a human Jurkat T-cell cDNA library (Stratagene) in $\lambda$ ZAP-II. Several screenings of $10^{6}$ plaques with the probes described in the Experimental section resulted in the detection of eight positive SERCA3 cDNA clones, Z1, Z3, Z4, Z8, Z9, Z10, Z17 and Z21, of which Z10 and Z21 ended in poly(A) tracts greater than 30 bases in length. Although the combined clones covered the whole open reading frame and the complete $3^{\prime}$ untranslated region, most of the $5^{\prime}$-untranslated region was still missing. In an effort to recover the $5^{\prime}$-untranslated region, a $\lambda$ gt11 cDNA library from human K562 cells (Clontech) was screened with a 427 bp EcoRI-BamHI probe corresponding to the $5^{\prime}$-end of clone Z8, which resulted in the identification of three more clones, $\mathrm{K} 1, \mathrm{~K} 2$ and $\mathrm{K} 3$, none of which contained any additional 5 ' sequence. For further applications, a composite clone, $\mathrm{pHS} 3$, was constructed from partial cDNA clones Z1, Z8, $\mathrm{Z} 10$ and Z17. The restriction map of clone pHS3 and the sequencing strategy for all clones isolated from both libraries are illustrated in Figure 1, and the composite nucleotide and deduced amino acid sequences are shown in Figure 2. Clone pHS3 is 4547 nucleotides in length and contains six nucleotides preceding the ATG codon (nt +1$)$, found in an acceptable context characteristic for initiation of eukaryotic translation [29]. A consensus polyadenylation signal [30] in the $1547 \mathrm{nt} 3^{\prime}$-untranslated region is located 17 nucleotides upstream of the beginning of the poly(A) tract. The $3^{\prime}$-untranslated region of human SERCA3 is $206 \mathrm{nt}$ longer than its rat counterpart.

\section{Amino acid sequence analysis and comparison with other SERCA pumps}

The primary translation product deduced from clone pHS3 is 999 amino acids in length. The predicted molecular mass of human SERCA3 is $109237 \mathrm{Da}$, close to the value of $109223 \mathrm{Da}$ for rat SERCA3 [11]. The hydrophobic domains, the phosphorylation site (residues 349-355) and other regions known to bind fluorescein isothiocyanate (FITC) or the ATP analogues FSBA (5'-p-fluorosulphonylbenzoyladenosine) and CIRATP $\{\gamma-[4-(N-$ 2-chloroethyl- $N$-methylamino)] benzylamide ATP ; [31-33] in SERCA1, and thought to be part of the ATP binding site, are conserved in human SERCA3 (Figure 3). In pairwise comparisons, human SERCA3 exhibits $94.3 \%$ overall identity with rat SERCA3, and $76.7 \%$ and $75.2 \%$ identity with human SERCA2a and human SERCA1a respectively. The sequence differences between human SERCA3 and the other SERCAs are mainly concentrated in the $\mathrm{N}$ - and $\mathrm{C}$-termini and in the regions flanking the FITC binding site. Except for the last 12 amino acids of their C-termini, there are 49 (usually scattered) differences between the human and rat SERCA3 isoforms. Sequence divergence among species in the C-terminus is further confirmed by immunological data (see below).

\section{Immunodetection of human SERCA3 in platelets and in transfected COS cells}

Two different antibodies (N89 and C90) directed respectively against an epitope close to the $\mathrm{N}$-terminus and against the extreme C-terminus of rat SERCA3 were recently obtained [13]. The N89, but not the C90, antiserum cross-reacted with the SERCA3 isoform from human platelets. A difference of seven out of $12 \mathrm{C}$-terminal amino acids deduced from the rat and human SERCA3 cDNAs explains the lack of reactivity with C90. A new antibody (C91), directed against the last 12 amino acids of the human isoform, specifically binds to the $\mathrm{Ca}^{2+}$-ATPase both in human platelets and in COS-1 cells transfected with human SERCA3 cDNA, but failed to recognize the $\mathrm{Ca}^{2+}$-ATPase from rat platelets and that expressed from rat SERCA3 cDNA in COS-1 cells. This is illustrated in Figure 4(A) (lanes 3-7), whereas an N89 immunostaining shown in Figure 4(B) (lanes 3-7) demonstrates specific binding to human and rat isoforms in platelets and COS-1 cells transfected with the corresponding cDNAs. The specificity of the $\mathrm{C} 90$ antibody is shown in Figure 4(C) (lanes 3 and 7), where the C91-immunostained blot was restained with $\mathrm{C} 90$.

\section{The C-terminal part of SERCA3 differs among species}

Western blot analyses were performed on cat, pig, rat and human platelets using the C90, N89 and C91 antisera. The immunostaining results are illustrated in Figures 4(A)-(C) (lanes 1-4). The N89 antibody cross-reacted with platelets from the four species, suggesting that the $\mathrm{N}$-terminal part of SERCA3 is conserved among these species. Cat and pig SERCA3 were not stained with either C91 or C90 antibodies, strengthening the idea of a more pronounced sequence variability within C-termini of SERCA3 from different mammals. The significance of this observation is not yet clear. There also exists a small but consistent difference in electrophoretic mobility of SERCA3 between the species. The human and the pig isoforms show a slightly lower mobility than the cat and rat isoforms. This can be most easily seen on SDS/PAGE (6\% gel) with extended running time (results not shown).

\section{Human SERCA3 does not display a PL/IM430-recognizable epitope}

Kovács et al. [21] suggested that human platelets express, besides the $100 \mathrm{kDa}$ SERCA2b and the $97 \mathrm{kDa}$ SERCA3, still another $97 \mathrm{kDa} \mathrm{Ca}^{2+}$-ATPase, which co-migrates with SERCA3 on SDS/polyacrylamide gels. This putative isoform selectively immunoreacted with the PL/IM430 monoclonal antibody, previously shown to inhibit $\mathrm{Ca}^{2+}$ uptake in platelet intracellular membrane vesicles [19]. This conclusion was apparently in contradiction with both our previous results [13] and those of 
ATGGAGGGGCGATCTGCTCCOCGG

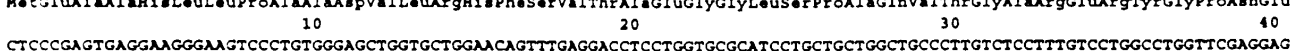

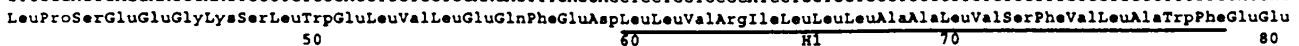
GGCSAGGAGACCACGACCGCCTCGTGGAGCCCCTGGTCATCATGCTGATCCTCGTGGCCUACGCCATTGTGGGCGTGTGGCAGGMCGCM CGCCGAGAGTGCCATCGAGGCCCTGMG

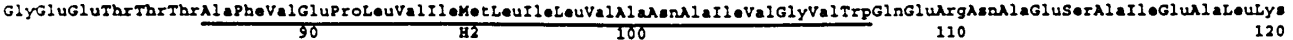
GAGTATGAGCCTGAGATGGGCAGGTGATCCGCTCGGACCGCAGGGCGTGCAGAGGATCCGTGCCCGGGACATCGTCCCAGGGGACATTGTAGMAGTGGCAGTGGGGGACMUGTGCCT

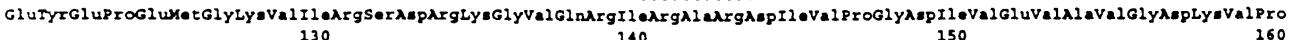

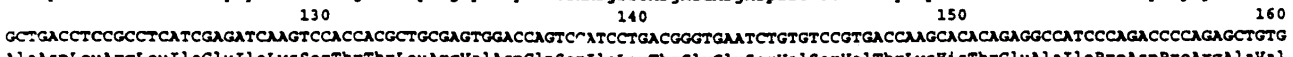

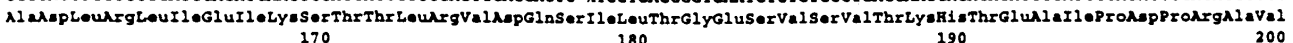
MCCAGGACUGUGMCATGCTGTTTRCTGGCACCUTATCACATCGGGCUUGCGGTGGGTGTGGCCETGCCACCGGCCTGCACACGGAGCTGGGCUGATCCGGAGCCAGATGGCG

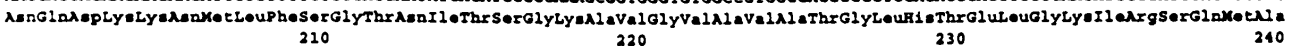
GCAGTCGAGCCCGAGCGGACGCCGCTGCAGCGCNAGCTGGACGAGTITGGACGGCAGCTGTCCCACGCCATCTCTGTGATCTGCGTGGCCGTGTGGGTCATCUACATCGGCCACTICGCC

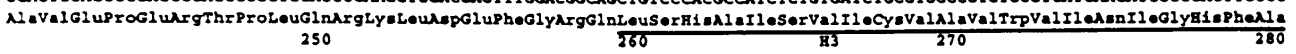
GACCCGGCCCACGGTGGCTCCTGGCTGCGTGGCGCTGTCTACTACTTCMAATCGCCGTGGCCCTGGCGGTGGCGOCCATCCCCGAGGGCCTCCCGGCTGTCATCACTACATGCCTGGCA

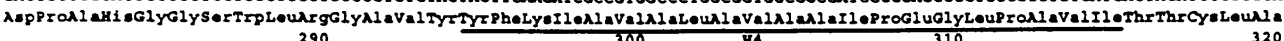
290
CTGGGCACGCGGCGATGGCACGCAMGMCGCCATCGTGCGMGCCTOCCGTCCGTGGAGACCCTGGGTGCACCTCAGTCATCTGCTCCGACMAGCOGGCACGCTCACCACCMTCAG
310

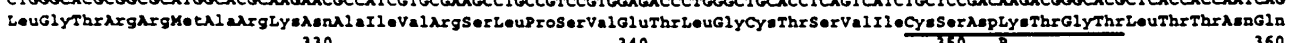

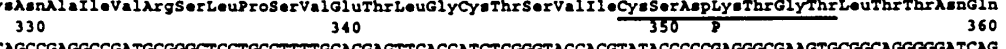
ATGTCTGTCTGCCGGATGTYCGTGGTAGCCGAGGCCGATGCGOGCTCCTOCCTITTGCACGAGTTCACCATCTCGGOTACCACGTATACCCCCGAGGGCGUAGTGCGGCAGGGGGATCAG

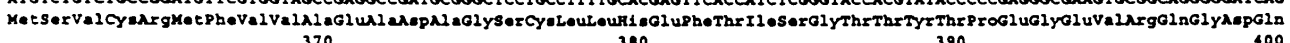

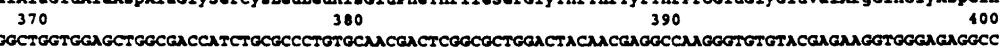

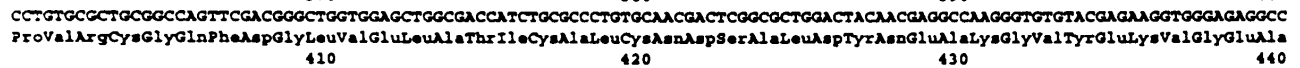

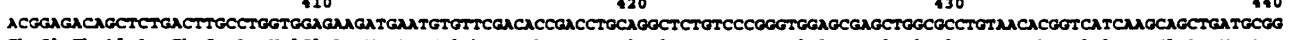

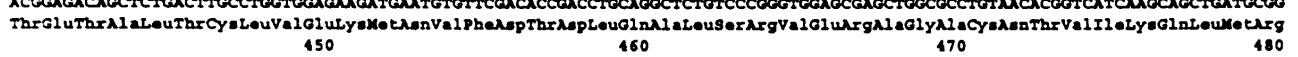
450
450

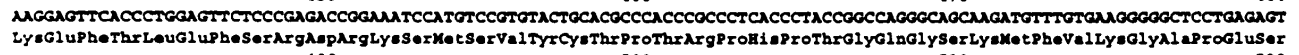

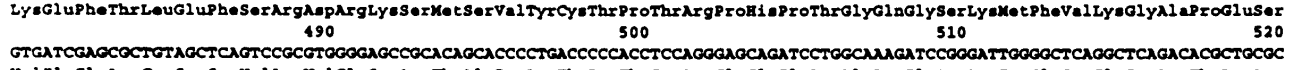

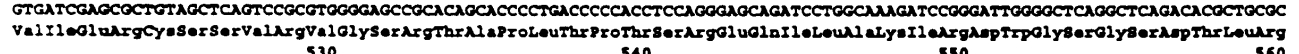
530
540 $530 \quad 560$

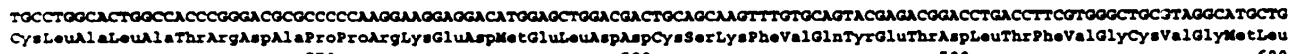

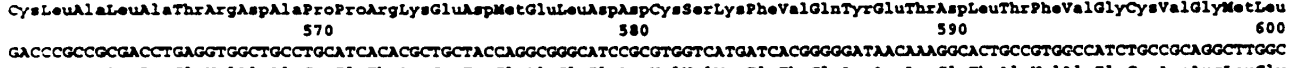

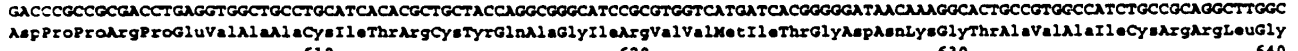

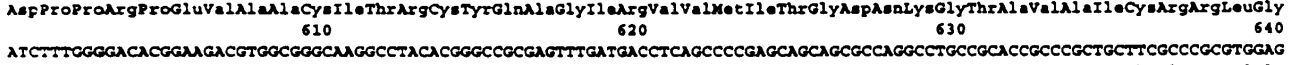

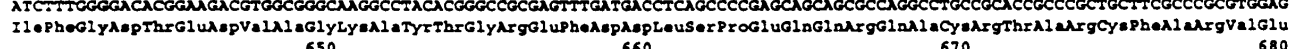

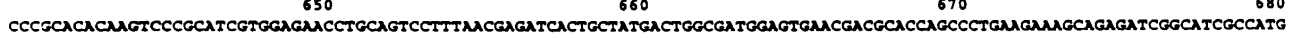

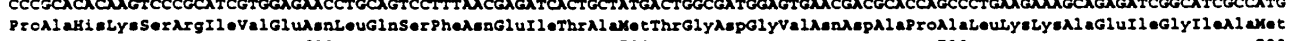

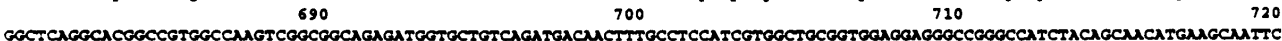

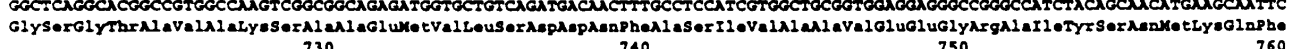
$730 \quad 740 \quad 750 \quad 760$

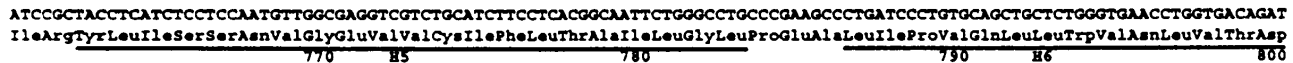

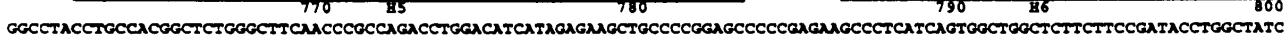

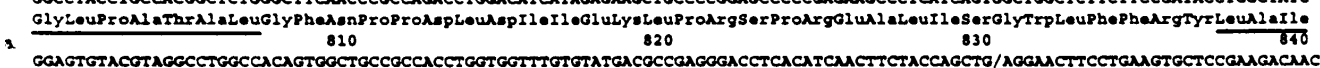

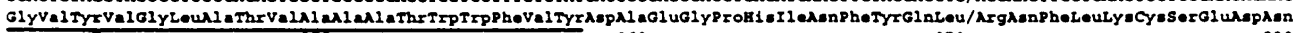

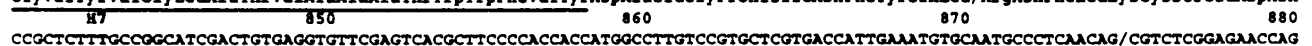

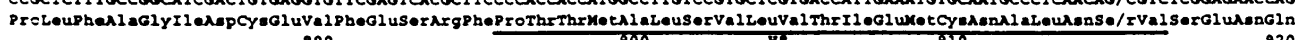

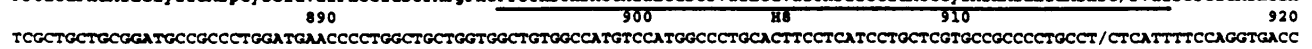

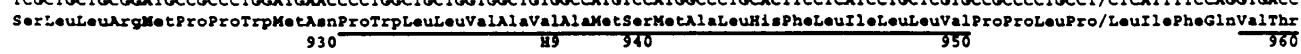
CCACTGAGCGGGCCCAGTGGOTGGTGGTGCTCCAGATATCTCTGCCTGTCATCCTGCTGGATGAGGCCCTCMATACCTGTCCCGGMCCACATGCACG/MAGMATGAGCCAGAMGTGA 3000

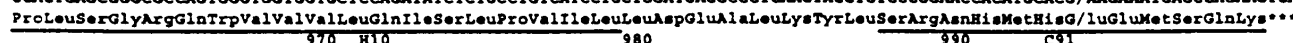
GCGCTQGGMACAGOGTGGAGTCTCCGGTGTGTACCTCAGACTGATGGTGCCCATGTGTTCGCCTCCGCCCCCCACCCTIGCCACCACACTCGCCCACTTGCCCACCGGGTCCCGCCGGAT GCGCTQGGM CAGOGTGGAGTCTCCGGTTGTACCTCAGACTGATGGTGCCCATGTGTTCGCCTCCOCCCCCCACCCTIGCCACCACACTCGCCCACTTGCCCACCGGGTCCCGCCOGAT

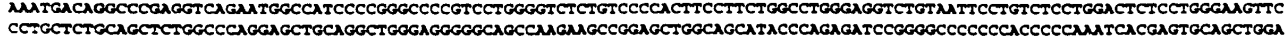

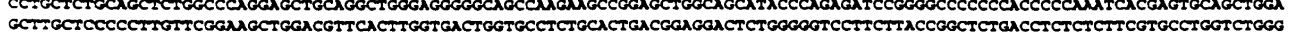

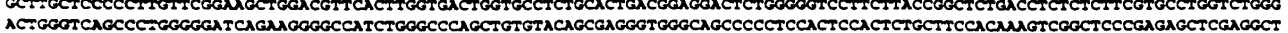

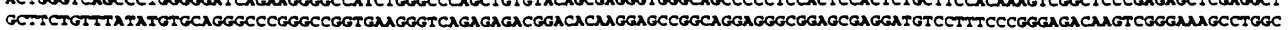
TGGACTGCCTCAGCCCCGCGCGCCTCCTGGACTCAGGGTICCCCTTCCTGAGCTCGGGAGATGTTCAGAGTCACACTGCCGCCCGGTCTGCCACGCAGAGGTCCM CTTGCCACCCGCGT CEC-GGTACCTGAGA CCACCGACATCCTCAGGTTCCTGACCGTGGCGCCCTTCAACCCAGCCCAGTGTGCGGCCGCCGCGCTGTCTGCACAGCTGGGGGCCTCTGAGCCTGGTGGGCTTC

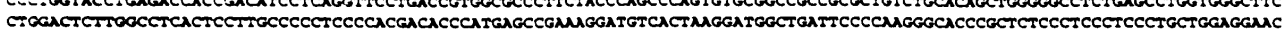

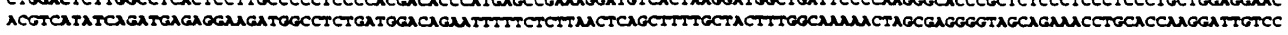

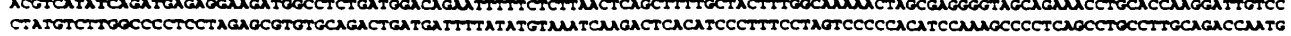

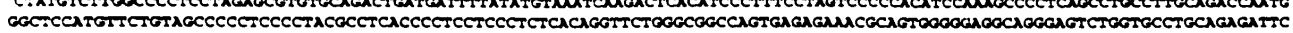

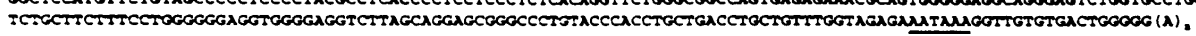

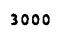

\section{0} 3240 3360 3480 3600 3720 3840 3960 4080
4200 4200
4320 4320
4440 4547

\section{Figure 2 Composite nucleotide and deduced amino acid sequences of human cDNA pHS3}

Nucleotides are numbered relative to the translation initiation site at the right of the sequence; amino acids are numbered below the sequence. The slashes in the sequence after nucleotides 2610 , 2744, 2862 and 2980 indicate the exon boundaries which were mapped from the gene. The phosphorylation site (P), the hydrophobic putative transmembrane domains (H1-H10) and the peptide C91 used to obtain C91 antisera are underlined and labelled. The consensus polyadenylation signal is underlined.

Bokkala et al. [20], who recently claimed that the protein recognized by PL/IM430 is SERCA3. cDNA cloning and transient expression of human SERCA3 cDNA in COS-1 cells clarified this controversy. Figure 4(D) shows that PL/IM430 stains a $97 \mathrm{kDa}$ band in human platelets but not in COS-1 cells expressing human SERCA3, in spite of the fact that N89 is able to detect low levels of its epitope. This analysis demonstrates that human SERCA3 does not contain a PL/IM430-recognizable epitope, thus supporting Kovács' idea of a multi-SERCA system in human platelets [21]. 


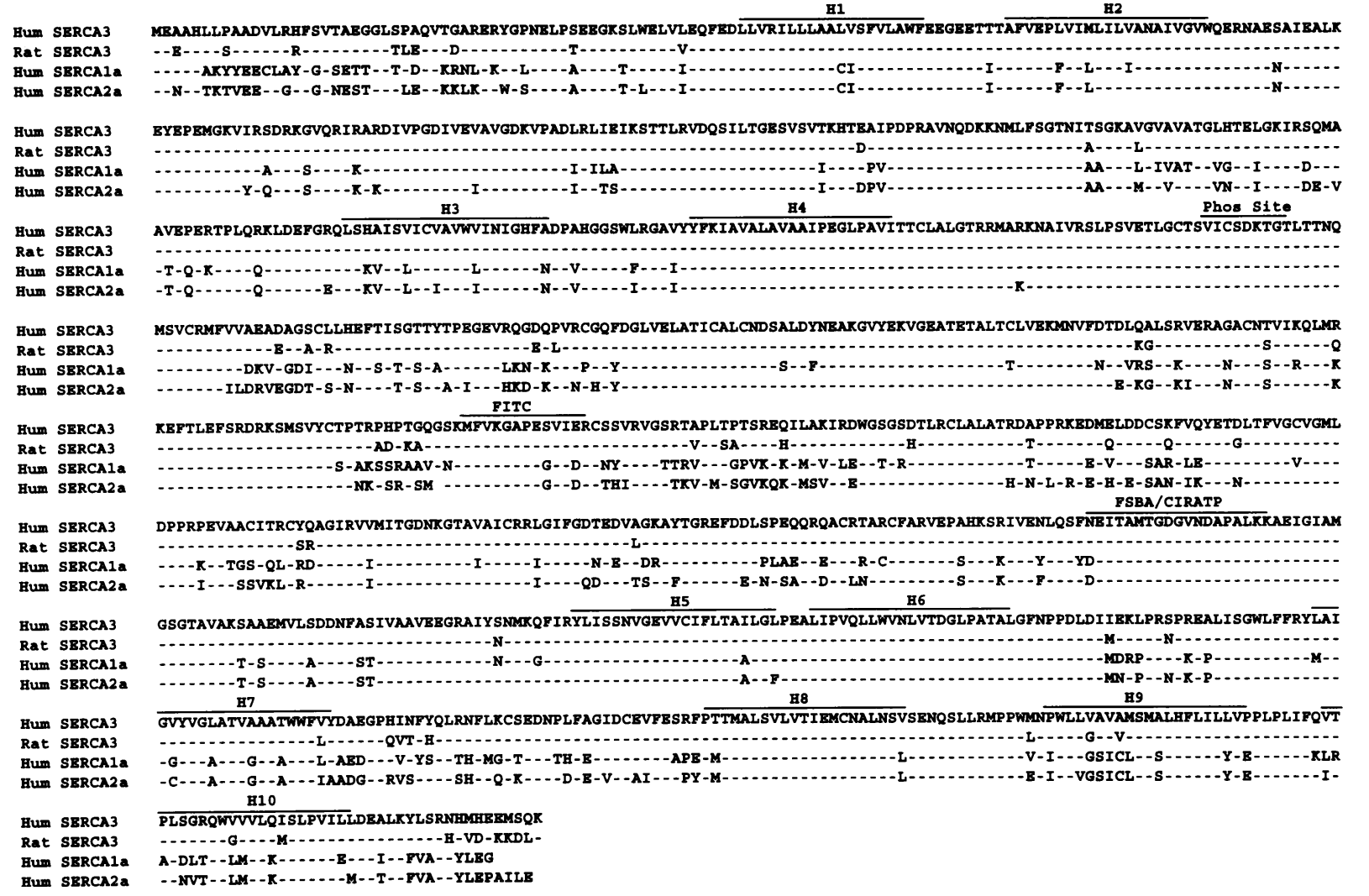

Figure 3 Amino acid similarity comparison

The deduced amino acid sequence of clone pHS3 (human SERCA3) is compared with those of rat SERCA3 [11], human SERCA1a [6] and human SERCA2a [8]. Residues of rat SERCA3, human SERCA1a and SERCA2a that are identical with the corresponding residues of human SERCA3 are represented by dashes. To maintain the alignment, a single gap was introduced in the SERCA2a sequence following residue 509. The amino acid numbers for human SERCA3 are shown on the right. The hydrophobic regions (H1-H10) which may represent transmembrane domains, the phosphorylation site (Phos Site), the FITC binding site [31] and the FSBA/CIRATP binding region [32,33] are labelled and indicated by bars above the sequence.

\section{Northern blot hybridization analysis}

The SERCA3 mRNA distribution pattern in various human tissues and cell lines was studied by Northern blot hybridization using probes from both the $5^{\prime}$-coding and the $3^{\prime}$-untranslated regions of clone pHS3 (Figure 5). Low levels of expression (in some cases only evident after longer exposures) of a $4.8 \mathrm{~kb}$ mRNA were detected with both probes in heart, brain, lung, stomach, thyroid and adrenal glands, whereas intermediate to high levels were found in bone marrow, pancreas, colon mucosa, K 562 cells, Jurkat cells, lymph nodes and trachea. Interestingly, analysis of the mRNA distribution using a $5^{\prime}$-end probe identified in thyroid gland and bone marrow an additional mRNA of $4.0 \mathrm{~kb}$ which was not recognized by the $3^{\prime}$-end probe. A $3.8 \mathrm{~kb}$ transcript detected in skeletal muscle with the $5^{\prime}$ probe but not with the $3^{\prime}$ probe can most likely be ascribed to a crosshybridization with the fast-twitch SERCA1 mRNA, which is expressed exclusively in this tissue at a very high level. The ubiquitously expressed $4.5 \mathrm{~kb}$ mRNA, coding for the housekeeping isoform SERCA2b, was not detected with any of the SERCA3-specific probes on our Northern blots. This is not surprising, since the $5^{\prime}$-end probe shares only $60 \%$ identity with the corresponding SERCA2b cDNA sequence. The $4.0 \mathrm{~kb}$ mRNA detected in thyroid and bone marrow should therefore most likely be attributed to SERCA3, thus providing the first evidence for alternative processing of the SERCA3 transcript.
Furthermore, Northern blot analysis using another 3 '-end probe, containing the entire untranslated region, showed that only the $4.8 \mathrm{~kb}$ mRNA was detected in thyroid and bone marrow (results not shown), indicating that the $4.0 \mathrm{~kb}$ mRNA uses a different polyadenylation signal which is not represented in the 3'untranslated region of the longer messenger. The difference in the relative distribution of the $4.0 \mathrm{~kb}$ and $4.8 \mathrm{~kb}$ mRNAs in thyroid ( $90 \%$ and $10 \%$ respectively) and bone marrow ( $40 \%$ and $60 \%$ respectively) may be relevant for the specific regulation of putative SERCA3 isoform expression in these tissues.

\section{Characterization of genomic clone GHS3 coding for the SERCA3 gene}

A genomic clone, GHS3, approx. $40 \mathrm{~kb}$ in length, was isolated by screening a human genomic library in the $\mathrm{pJB} 8$ cosmid vector with a rat $N o t \mathrm{I}-B g / \mathrm{II}$ cDNA probe. Southern blot hybridization analysis showed that the coding regions of the SERCA3 gene recognized by this cDNA probe were spread over a genomic region of $25 \mathrm{~kb}$. The restriction map of the genomic insert is illustrated in Figure 6. A more detailed examination, using a Not I-PvuI fragment as $5^{\prime}$ probe and a $S n a \mathrm{BI}-\mathrm{Bg} / \mathrm{II}$ fragment as $3^{\prime}$ probe, revealed that the $5^{\prime}$-end of the gene was not represented in clone GHS3, whereas the $3^{\prime}$-region of the SERCA3 gene was retained. This observation was further confirmed by Southern blot analysis with human cDNA probes. 


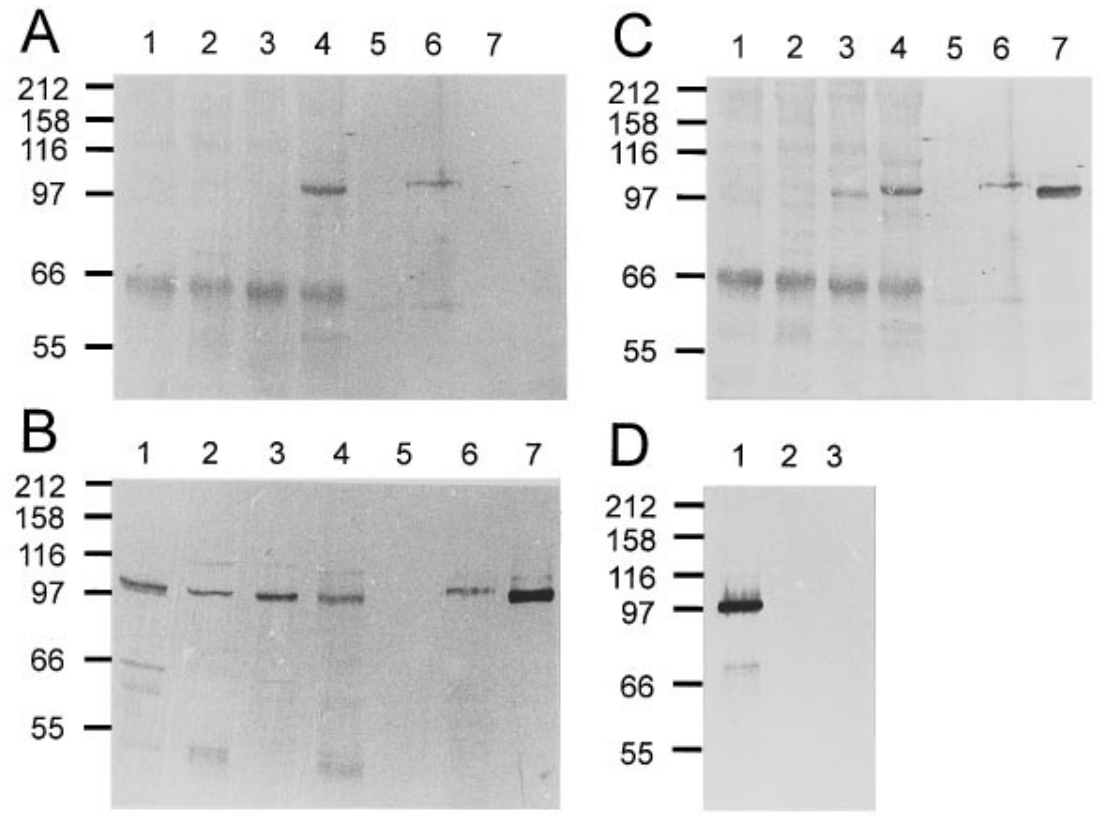

Figure 4 Immunoblot analysis of SERCA3 expression in platelets from different species and in COS-1 cells transfected with human and rat cDNAs

Samples of $40 \mu \mathrm{g}$ of protein/lane of platelet microsomes (A-C: lane 1, cat; lane 2, pig; lane 3, rat; lane 4, human; $\mathbf{D}$ : lane 1, human) and of $50 \mu \mathrm{g}$ of protein/lane of the intracellular membranerich nuclear fraction from COS cells transfected with no CDNA (A-C, lane 5; D, lane 2), human SERCA3 CDNA (A-C, lane 6; D, lane 3) or rat SERCA3 CDNA (A-C, lane 7) were electrophoresed on Laemmli gels, semi-dry blotted and immunostained as indicated in the Experimental section. The blot shown in (A) was first stained with the human SERCA3-specific antiserum C91 (1:500 dilution). The same blot was then overstained with the rat SERCA3-specific antiserum C90 (1:1000 dilution) as shown in (C). Immunostaining with the SERCA3-directed antibody N89 (1:1000 dilution) is shown in (B), whereas (D) illustrates staining with the monoclonal antibody PL/IM430 (1:1000 dilution). Positions of molecular mass standards (KDa) are indicated.

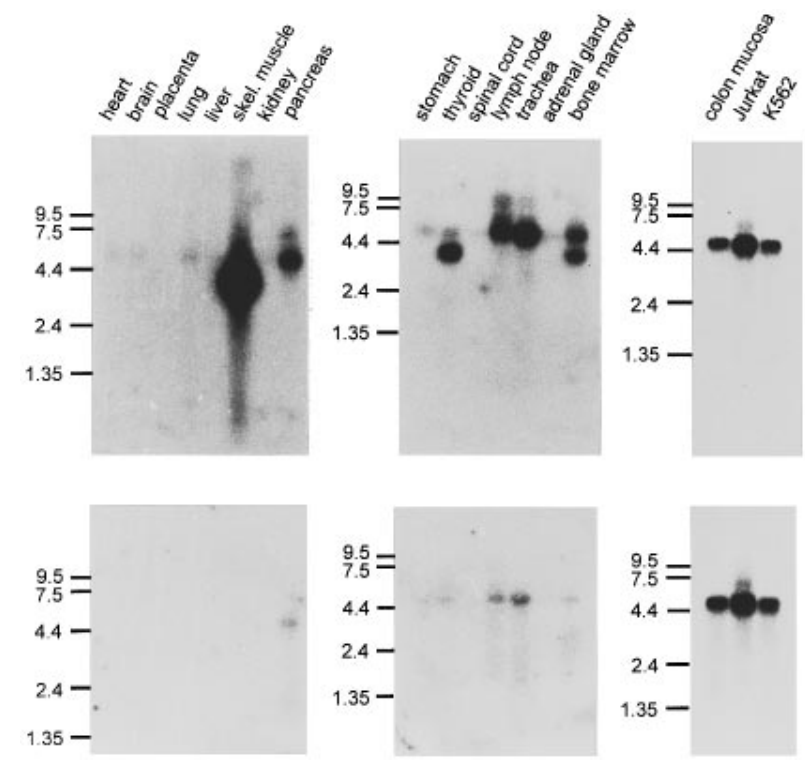

Figure 5 Tissue distribution of the mRNA encoding human SERCA3

Poly $(A)^{+}$RNA from the indicated human tissues or cell lines was analysed by Northern blot hybridization using probes from the $5^{\prime}$-coding region (upper row) and the $3^{\prime}$-untranslated sequence (lower row) of clone pHS3, as indicated in the Experimental section. The autoradiographic exposure time was $48 \mathrm{~h}$ at $-80^{\circ} \mathrm{C}$. The positions and sizes (in $\mathrm{kb}$ ) of the RNA markers (Gibco-BRL) are shown on the left of each blot.

Our Northern blot analysis identified a new SERCA3 transcript and, since no data regarding gene structure have been reported so far, it was of interest to investigate the structure of

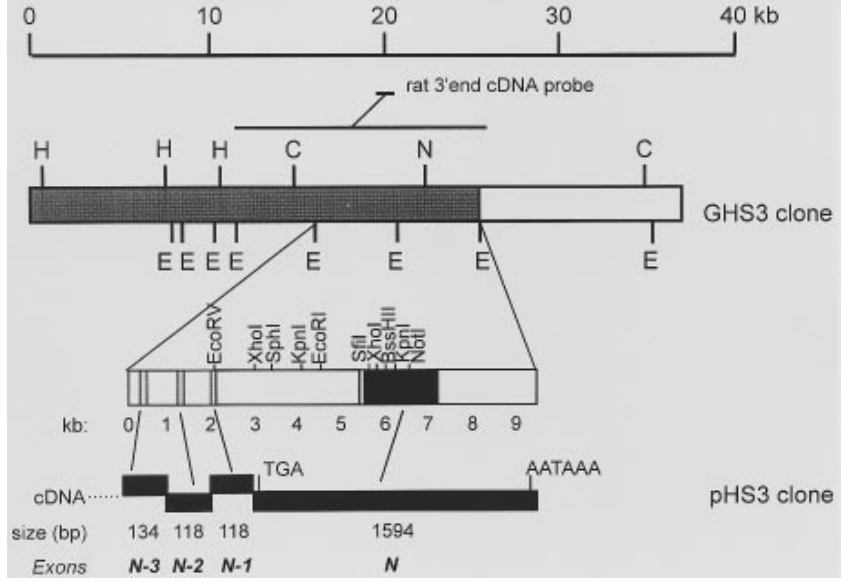

Figure 6 Restriction map of the genomic clone GHS3 and partial structure of the human SERCA3 gene

The restriction map of the clone GHS3 is shown below the scale line. The shaded box represents the genomic sequence encoding all but the $5^{\prime}$ region of the gene. The bar above the map illustrates the restriction fragments which hybridized to the indicated cDNA probe. C, Clal; E, EcoRl; H, Hindlll; N, Nott. An enlargement of a $9.5 \mathrm{~kb}$ genomic region encoding the last four exons of pHS3 is shown below clone GHS3; the light grey boxes represent the coding regions and the black box represents the $3^{\prime}$-untranslated sequence. The splicing pattern and the sizes of the exons (not to scale) are displayed beneath the enlargement. The stop codon (TGA) and the polyadenylation signal AATAAA [30] are also indicated.

the $3^{\prime}$-end of the gene in order to evaluate the likelihood of an alternative splicing event. Exon/intron boundaries are likely to be conserved in related genes. Based on the published exon/intron layout of the SERCA1 gene [5,6] and on that of the 3'-end of the 
2611 Exon $N-3$

CagAGGAACTTCCTGAAGTGCTCCGAAGACAACCCGCTCTTTGCCGGCATCGACTGTGAG ArgAsnPheLeuLysCysSerGluAspAsnProLeuPheAlaglyIleAspCysGlu 871

GTGTTCGATCACGCTTCCCCACCACCATGGCCTTGTCCGTGCTCGTGACCATTGAAATG ValPheGluSerArgPheProThrThrMetAlaLeuSerValLeuValThrIleGluMet 2744

TGCAATGCCCTCAACAGgtaggetgggcgcagggcetggagctggggccgaggagtgggg CYSAsnAlaLeUAsnSe

915

gctgagggctgggggttccagtatcagtgtctgagggt...( 0.76kb) ...tcccatg ggggtgggtgcctggcagggectccetgcaccccggectaaggggagcaccctgtgccet

2745 Exon $N-2$

ggcagCGTCTCGGAGAACCAGTCGCTGCTGCGGATGCCGCCCTGGATGAACCCCTGGCTG rValSerGluAsnGlnSerLeuLeuArgMetProProTrpMetAsnProTrpLeu 916

CTGGTGGCTGTGGCCATGTCCATGGCCCTGCACTTCCTCATCCTGCTCGTGCCGCCCCTG LeuValAlaValAlaMetSerMetAlaLeuHis PheLeuIleLeuLeuVal ProProLeu 2862

CCTgtgagtcacccegcetgcccactgccetggtccetggacatcacaggcctggget Pro

954

ggtcactggacctctctggccccctgcaatggaaactacctggaggagagggaggtgag aggtctggc . . (547 bp) . . agggggttcttaggagtgctcatgaagagtccatcag agcccaggtggataaggccagcagatggctggggcacgggacagccagtccttcctttaa 2863 ExOn $N-1$

ccaaacctccettcccetccccgccagCTCATTTTCCAGGTGACCCCACTGAGCGGGCGC LeuIlePheGlnValThrProLeuSerGlyArg 955

CAGTGGGTGGTGGTGCTCCAGATATCTCTGCCTGTCATCCTGCTGGATGAGGCCCTCAAG GlnTrpValValValLeuGlnIleSerLeuProValIleLeuLeuAspgluAlaLeuLys 2980

TACCTGTCCCGGAACCACATGCACGgtgagtgggaggeccegtcccgectccagcetgeC TyrLeuSerArgAsnHisMetHisG 993

tccccgccogcctctgctcctgggetgcagtggacgctgtgggtgtggagcgcagagcet ctctgtctgcacatcggggaggcgttctcggatcaccaagtggagggtgtgaaggggetc tggtggctgggtcccaaggtgtccgcaggtcttgcactgcaggggacctgggctcactgg gccagcaacgggagcacctcttgggccacactgectcactgtcttcacctgccacccct acatggccagggcactgtgtgctcttctgggcctcagcctctgaccctctgcacccagc ctgtctttatccaggccttctcaggacagtctcgcaggcetggagtaggcagccgctgac cacctcttggacccagaccacaccgggttggcctctttggtatcaccttgtgggtgggt caaggggagggttgtttctgagctcacagctctgggtctgccttaaccceggagtggaga ggacaggatggcaggtgtcgggctggagagaagtgggetgggacatggggtccatccacc tgcctc... (3218 bp) ...gtgaaggaggcgtgggggacgttgcggggatggatcctg gatgcagcttggggggtccggtggggetggggtagactgaggtctggactaagggaggec ttgggagcctggggetgtcctgggagaagtggaggatggaaggggctggaaggaagctgt 2981

ctggatgtgtgcccttacacatacatcttaacgcgctcttgggttttcttccagAAGAA

\section{Exon $\boldsymbol{N}$}

luGlu

ATGAGCCAGAAGTGAGCGCTGGGAACAGGGTGGAGTCTCCGGTGTGTACCTCAGACTGAT

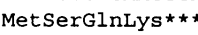

999

GGTGCCCATGTGTTCGCCTCCGCCCCCC . . . (1594 bo ) . . . TCCCTCTCACAGGTTCT GGGCGGCCAGTGAGAGAAACGCAGTGGGGGAGGCAGGGAGTCTGGTGCCTGCAGAGATTC TCTGCTTCTTTCCTGGGGGGAGGTGGGGAGGTCTTAGCAGGAGCGGGCCCTGTACCCACC 4547

TGCTGACCTGCTGTTTGGTAGAGAAATAAAGGTTGTGTGACTGGGGGaacggaggatcct cagcgtctgttttcctggggagtggtcccgccgtctccacctatggggcgtctgcctggg gccetaccacctgcccataccacctgcceataccacctgcccacacccagtccaggaaac getgagcaaaggtctggggttcacacatcaccaggattgctccct

\section{Figure 7 Partial genomic nucleotide sequence and exon/intron layout of the $3^{\prime}$-end of the human SERCA3 gene}

The exon sequences are shown in upper-case letters and the intervening sequences are shown in lower-case. The positions of the nucleotides at the exon/intron boundaries are indicated above the nucleotide sequence and numbered relative to the translation initiation site. The underlined nucleotide (c) represents the start of the $5.7 \mathrm{~kb}$ nucleotide sequence deposited in the EMBL/GenBank Data Bank under accession no. Z69880. The positions within the coding sequence of the protein are indicated below the amino acid sequence. The polyadenylation signal is shown in bold face. The nucleotide at position 4547 is polyadenylated in clone pHS3, but see the Results section for comments. The sizes of the introns and the last exon are also indicated.

SERCA2 gene [8], PCR primers for human SERCA3 were chosen in the exonic regions flanking each putative intron. In this way the presence of an intron could be confirmed and its total length assessed. Additionally, the same PCR primers were used as oligonucleotide probes on Southern blots in order to identify the genomic restriction fragments containing the corresponding exon sequences. This approach resulted in the identification of three adjacent fragments estimated to cover a total length of $9.5 \mathrm{~kb}$ of genomic DNA. The $2.1 \mathrm{~kb} E c o \mathrm{RI}-E c o \mathrm{RV}$, the $4.3 \mathrm{~kb}$ EcoRV-NotI and the $3.1 \mathrm{~kb}$ NotI-EcoRI fragments (see Figure 6) were subcloned for further analysis. The $9.5 \mathrm{~kb}$ genomic region contained the four terminal exons and the corresponding three intervening sequences. The sizes of the antepenultimate, penultimate and ultimate introns as determined by PCR were $0.76,0.55$ and $3.1 \mathrm{~kb}$ respectively. All exons, exon/intron boundaries and introns (except for the antepenultimate one) were sequenced in both directions, and the complete nucleotide sequence of more than $5.7 \mathrm{~kb}$ of genomic DNA is shown in Figure 7. The most 5 ' exon (exon $\mathrm{N}-3$ in Figure 6) codes for a protein region extending from amino acid 871 to 914 (nt 2611-2744 of the pHS3 clone). The next exon (exon $\mathrm{N}-2$ ) codes for amino acids 915-954 (nt 2745-2862 of pHS3), whereas the penultimate exon (exon $\mathrm{N}-1$ ) codes for amino acids 955-993 (nt 2863-2980 of pHS3). The coding region for amino acids 994-999 and the whole 3'-untranslated sequence of human SERCA3 cDNA are found in the last exon (exon N), which is probably the largest exon (1567 nt long) found in the SERCA3 gene. GT and AG dinucleotides were found at the $5^{\prime}$ - and $3{ }^{\prime}$-ends respectively of each of the intervening sequences. The positions of the $\mathrm{N}-3, \mathrm{~N}-2$ and $\mathrm{N}-1$ exons perfectly match with those of exons 19, 20 and 21 respectively of the rabbit and human SERCA1 genes [5,6] and with the similar exons of the human SERCA2 gene [8]. Exon 21 represents the last constitutive exon in SERCA1 and SERCA2. The 3' limit of this exon (nt 2980 in human SERCA3) represents in both cases the point of divergence between the different splice variants. Exons downstream of this are optional and their excision/retention is developmentally or tissue-specifically regulated. A perfect polyadenylation consensus sequence [30], AATAAA, was found 17 nucleotides upstream of the beginning of the poly $(\mathrm{A})^{+}$tail. It is impossible on the basis of sequence analysis alone to determine the exact position of the cleavage/polyadenylation site, since the nucleotide $\mathrm{G}$ at position 4547 is followed by two A nucleotides at positions 4548 and 4549 in the gene. A similar ambiguous situation was encountered in the human SERCA2 gene [8]. Other polyadenylation signals, which could give us a clue to understanding the generation of the two transcripts observed in Northern blot experiments, were not detected in either the ultimate intron sequence or the 3'untranslated region. We cannot exclude the possibility that an optional exon corresponding to the $3^{\prime}$-end of the $4.0 \mathrm{~kb}$ transcript may still be found in the SERCA3 gene, downstream of exon N.

\section{Chromosomal localization of the human SERCA3 gene by FISH}

Biotin-11-dUTP-labelled DNA of clone GHS3 was used as a probe for FISH. Analysis of 20 metaphase spreads allowed us to localize the SERCA3 gene on the short arm of chromosome 17 to region p13.3, based on G-banding. Over $80 \%$ of the metaphases displayed strong paired signals and others showed strong single signals combined with a weaker paired signal. No crosshybridizations to the other members of SERCA gene family were detected. Figure 8 illustrates a typical example of a FISH experiment and the corresponding G-banding pattern of the human metaphase chromosomes. Guided by FISH analysis results, we subsequently screened a human chromosome-17specific cosmid library available as gridded filters from Reference Library Database ICRF [34], and six new overlapping positives coding for the SERCA3 gene were isolated (ICRFc105-A09183, 

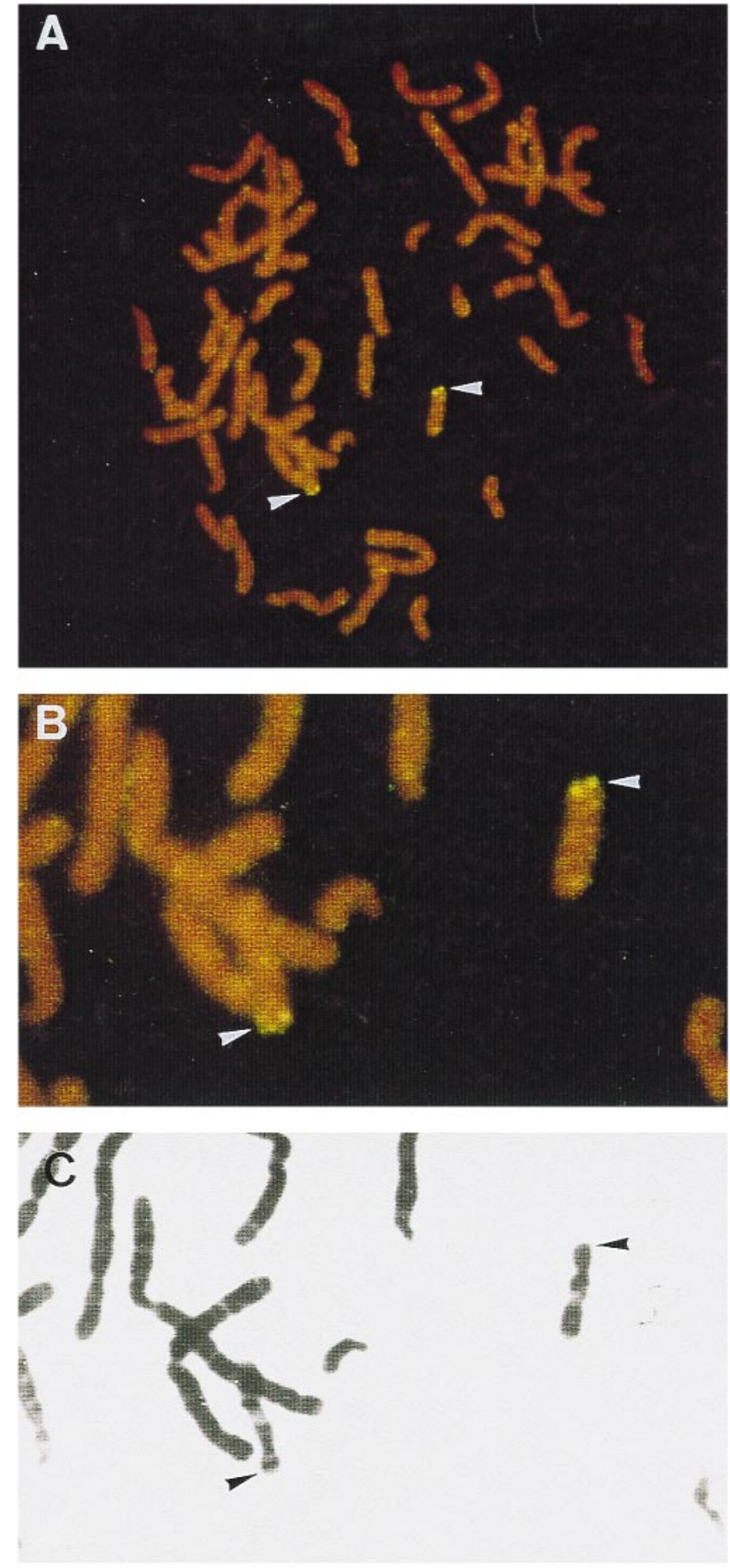

Figure 8 Chromosomal localization of the human SERCA3 gene (ATP2A3)

(A) Example of FISH analysis of a metaphase spread using the biotin-11-dUTP-labelled cosmid DNA GHS3 as probe. The hybridization signals on human chromosomes 17 are indicated with arrowheads. (B) Enlargement of the same FISH experiment. (C) Chromosome G-banding pattern of the same metaphase spread; the arrowheads show the places where the FISH signals were observed.

-C10135, -G1035, -G09189, -F10124 and -F021). Preliminary data show that these clones cover a genomic region of about $90 \mathrm{~kb}$ (results not shown).

\section{DISCUSSION}

\section{Molecular cloning and transient expression of human SERCA3 cDNA}

Previous work $[13,14]$ established that the SERCA3 pump is expressed in both rat and human platelets. Additonally, Western blot analyses using polyclonal SERCA3-specific antibodies (N89 and C90) suggested that the rat and human isoforms are immunologically distinct. A monoclonal antibody, PL/IM430, was previously described and shown to inhibit $\mathrm{Ca}^{2+}$ uptake in intracellular membranes from human platelets, but its reaction appeared to be strictly confined to human epitopes [19]. Since it recognized a protein with the same apparent molecular mass as SERCA3 (97 kDa in acid PAGE gels), it was initially assumed that human SERCA3 corresponded to the PL/IM430-recognizable $\mathrm{Ca}^{2+}$-ATPase $[13,20]$. Based on controlled trypsinolysis of the human platelet $\mathrm{Ca}^{2+}$-ATPases and subsequent PL/IM430 immunostaining of the fragments, Kovács et al. [21] proposed the existence of a $97 \mathrm{kDa} \mathrm{Ca}{ }^{2+}$-ATPase isoform distinct from SERCA3. However, the possibility that the C-terminus of the human SERCA3 protein might contain the PL/IM430-recognizable epitope could not be excluded. To further test the hypothesis that human platelets indeed co-express two distinct $97 \mathrm{kDa}$ isoforms, human SERCA3 cDNA was cloned and transiently expressed in COS-1 cells, which do not express endogenous SERCA3 [18]. Remarkably, the expression levels of the human SERCA3 protein in the COS cell system were much lower than those obtained in our previous expressions of rabbit SERCA1a, pig SERCA2a and SERCA2b [13], in spite of the production in the COS cells of high levels of human SERCA3 mRNA as indicated by reverse transcriptase-PCR (results not shown). We have as yet no good explanation for this reduced expression. The human SERCA3 expressed in COS cells could be immunodetected not only by the previously described N89 SERCA3-specific antibody, but also by a new human-SERCA3specific antibody (C91) directed against the extreme 12-aminoacid C-terminal tail of human SERCA3, deduced from the cDNA sequence presented here. Whereas the N89 and C91 antisera were able to recognize both endogenous SERCA3 in human platelets and SERCA3 expressed from its cDNA in COS cells, PL/IM430 gave a positive reaction only in human platelets. This evidence is complementary to the studies of Kovács [21] and supports the idea of the expression of a multi-SERCA system in platelets and in some other related human cells. It should be noted, however, that the possibility that the lack of reactivity of PL/IM430 with expressed human SERCA3 in COS cells results from a failure of the enzyme to reach its appropriate native conformation cannot be entirely excluded.

An important issue concerns identification of the structural domains of the SERCA pumps, which might be involved in their specific subcellular targeting. In view of the analogy between the C-terminal end of the adenovirus E19 protein and rat SERCA3, Burk et al. [11] suggested that the C-terminal sequence of rat SERCA3, comprising the last 15 amino acids, might function as an endoplasmic reticulum retention signal. The motif, which consists of two lysine residues located three amino acids upstream of the C-terminus, also resembles that found at the C-terminal part of some endoplasmic reticulum membrane proteins [35]. A comparison between human and rat SERCA3 C-termini (Figure 3) shows that the rat putative endoplasmic reticulum retention signal is not conserved in the human isoform. Moreover, our immunoblot analyses (Figure 4) suggest that the C-terminal sequences of mammalian SERCA3 pumps present, in general, a lower degree of conservation than was observed for the other members of the SERCA family. Furthermore, both SERCA1 
and SERCA2 isoforms lack the retention signal. Taken together, these observations imply that other regions, normally conserved amongst all SERCA pumps, are actually involved in the targeting process. A recent study using chimaeric constructs comprising SERCA and plasma membrane $\mathrm{Ca}^{2+}$-ATPase domains showed that the first transmembrane domain of the SERCA component was required for efficient retention in the endoplasmic reticulum [36].

\section{Alternative processing of the SERCA3 primary transcript}

The partial characterization of the intron positions in the SERCA3 gene shows that the exon/intron boundaries are highly conserved among the members of the mammalian SERCA family. The developmentally controlled or tissue-dependent alternative processing of SERCA1 and SERCA2 primary transcripts respectively has been well documented [2]. The protein isoforms resulting from this processing (SERCA $1 \mathrm{a} / 1 \mathrm{~b}$ and SERCA $2 \mathrm{a} / 2 \mathrm{~b}$ ) are characterized by an altered amino acid sequence in their extreme C-terminal regions. Our Northern blot hybridization analysis (Figure 5) from different human tissues and cell lines suggests the possibility of a similar alternative splicing affecting the C-terminus of human SERCA3. Indeed, it not only confirms the non-muscle distribution of a $4.8 \mathrm{~kb}$ SERCA3 mRNA but also reveals an unexpected pattern consisting of two transcripts, of 4.8 and $4.0 \mathrm{~kb}$, in thyroid gland and in bone marrow. The $4.0 \mathrm{~kb}$ mRNA was detected with the 5 -end probe but not with the 3 '-end probe. The 374-bp-long 3'-end probe (stretching from 16 to 390 bp downstream of the stop codon) did not detect the $4.0 \mathrm{~kb}$ mRNA species, even under low-stringency washing conditions. Similar results were obtained with a probe comprising the whole 3'-untranslated region. This is the first evidence suggesting that SERCA3 pre-mRNA might also be alternatively processed.

The 3'-end of the human SERCA3 gene was cloned in order to better evaluate the possible mechanisms by which the two observed transcripts might be generated. This revealed that the last exon found in the $4.8 \mathrm{~kb}$ transcript encodes the last six Cterminal amino acids of the protein and the entire 3 '-untranslated region. The preceding $3.1 \mathrm{~kb}$ intron does not present any obvious polyadenylation signal which could be used by the $4.0 \mathrm{~kb}$ transcript. Hence the $4.0 \mathrm{~kb}$ mRNA found in thyroid and bone marrow most likely contains a coding sequence for a $\mathrm{C}$-terminus and a $3^{\prime}$-untranslated region, which are not found in either the terminal intron or the last exon retained in the $4.8 \mathrm{~kb}$ mRNA, but more downstream in the gene. This implies that the transcript processing mode for human SERCA3 differs from the exon skipping (SERCA1) and the internal donor site splicing (SERCA2) models. The SERCA3 processing mode may instead resemble that described for the calcitonin/calcitonin-gene-related peptide gene [37] and for the Drosophila double sex, dsx [38] genes. Until a cDNA clone corresponding to the $4.0 \mathrm{~kb}$ transcript is isolated, it remains an open question as to which splicing model is characteristic for SERCA3.

\section{Chromosomal localization of the human SERCA3 gene}

Previous studies [39-41] demonstrated that the genes encoding the SERCA1 and 2 isoforms (ATP2A1 and ATP2A2) are localized to human chromosomes $16 \mathrm{p} 12.1$ and $12 \mathrm{q} 23$-q24.1 respectively. We now report assignment of the SERCA3 gene (ATP2A3) to human chromosome $17 \mathrm{p} 13.3$, a cytogenetic band frequently associated with loss of heterozygosity for different diseases. This localization was further confirmed by the isolation of six new overlapping genomic clones, coding for the SERCA3 gene, from a chromosome-17-specific library. The estimated size of the cytogenetic sub-band $17 \mathrm{p} 13.3$ accounts for 3-4 Mbp, and genes involved in the growth and development of the nervous system have been mapped to this region: the Miller-Dieker lissencephaly gene LYSI [42] and a putative suppressor gene, distinct from $\mathrm{p} 53$, involved in medulloblastoma [43]. Recent work on rat brain has provided evidence that the SERCA3 gene is expressed in cerebellar Purkinje neurons along with the housekeeping gene, SERCA2 [16,17]. The chromosomal mapping of the SERCA3 gene could be useful for the investigation of how closely these unrelated genes are physically linked, and the Not Ilinking clone GHS3 represents a valuable tool for the long-range NotI restriction map project of this region. Given the extensive gene conservation between human chromosome 17 and mouse chromosome 11 [44], it would not be surprising to find that the mouse SERCA3 gene is localized on mouse chromosome 11. Further characterization of the ICRF cosmid clones is needed in order to analyse the promoter region of SERCA3. This can provide further insight regarding the distribution of SERCA3 in non-muscle tissues.

We thank Dr. Gary E. Shull (Department of Molecular Genetics, Biochemistry and Microbiology, University of Cincinnati, Cincinnati, OH, U.S.A.) for the gift of the rat cDNA clone RK 8-13, Dr. Randal J. Kaufman (Genetics Institute, Boston, MA, U.S.A.) for providing the expression vector pMT2, and Dr. Kalwant S. Authi (Thrombosis Research Institute, London, U.K.) for the gift of the monoclonal antibody PL/IM430. We gratefully acknowledge the Reference Library, ICRF, London, U.K., for providing both the gridded filters of the human chromosome-17-specific cosmid library and the positive clones. We thank Dr. Hilde Verboomen, Laboratorium voor Fysiologie, for help with the COS cell expression system. We also thank Yves Parijs, Anja Floorizone and Raphael Verbist for their skilful technical assistance.

\section{REFERENCES}

1 Pozzan, T., Rizzuto, R., Volpe, P. and Meldolesi, J. (1994) Physiol. Rev. 74, 595-636

2 Wuytack, F., Raeymaekers, L., De Smedt, H., Eggermont, J. A., Missiaen, L., Van Den Bosch, L., De Jaegere, S., Verboomen, H., Plessers, L. and Casteels, R. (1992) Ann. N. Y. Acad. Sci. 671, 82-91

3 Brandl, C. J., Green, N. M., Korczak, B. and MacLennan, D. H. (1986) Cell 44, 597-607

4 Brandl, C. J., DeLeon, S., Martin, D. and MacLennan, D. H. (1987) J. Biol. Chem. 262, 3768-3774

5 Korczak, B., Zarain-Herzberg, A., Brandl, C. J., Ingles, C. J., Green, N. M. and MacLennan, D. H. (1988) J. Biol. Chem. 263, 4813-4819

6 Zhang, Y., Fujii, J., Phillips, M. S., Chen, H.-S., Karpati, G., Yee, W.-C., Schrank, B., Cornblath, D. R., Boylan, K. B. and MacLennan, D. H. (1995) Genomics 30, 415-424

7 de la Bastie, D., Wisnewski, C., Schwartz, K. and Lompré, A.-M. (1988) FEBS Lett. 229, 45-48

8 Lytton, J. and MacLennan, D. H. (1988) J. Biol. Chem. 263, 15024-15031

9 Gunteski-Hamblin, A., Greeb, J. and Shull, G. E. (1988) J. Biol. Chem. 263, 15032-15040

10 Eggermont, J., Wuytack, F. and Casteels, R. (1990) Biochem. J. 266, 901-907

11 Burk, S. E., MacLennan, D. H. and Shull, G. E. (1989) J. Biol. Chem. 264 18561-18568

12 Wuytack, F., Dode, L., Baba-Aissa, F. and Raeymaekers, L. (1995) Biosci. Rep. 15, 299-306

13 Wuytack, F., Papp, B., Verboomen, H., Raeymaekers, L., Dode, L., Bobe, R., Enouf, J., Bokkala, S., Authi, K. S. and Casteels, R. (1994) J. Biol. Chem. 269, 1410-1416

14 Bobe, R., Bredoux, R., Wuytack, F., Quarck, R., Kovács, T., Papp, B., Corvazier, E., Magnier, C. and Enouf, J. (1994) J. Biol. Chem. 269, 1417-1424

15 Anger, M., Samuel, J.-L., Marotte, F., Wuytack, F., Rappaport, L. and Lompré, A.-M. (1993) FEBS Lett. 334, 45-48

16 Wu, K.-D., Lee, W.-S., Wey, J., Bungard, D. and Lytton, J. (1995) Am. J. Physiol. 269, C775-C784

17 Baba-Aissa, F., Raeymaekers, L., Wuytack, F., Callewaert, G., Dode, L., Missiaen, L. and Casteels, R. (1996) Mol. Brain Res., in the press

18 Lytton, J., Westlin, M., Burk, S. E., Shull, G. E. and MacLennan, D. H. (1992) J. Biol. Chem. 267, 14483-14489

19 Hack, N., Wilkinson, J. M. and Crawford, N. (1988) Biochem. J. 250, 355-361

20 Bokkala, S., El-Daher, S. S., Kakkar, V. V., Wuytack, F. and Authi, K. S. (1995) Biochem. J. 306, 837-842

21 Kovács, T., Corvazier, E., Papp, B., Magnier, C., Bredoux, R., Enyedi, A., Sarkadi, B. and Enouf, J. (1994) J. Biol. Chem. 269, 6177-6184 
22 Feinberg, A. P. and Vogelstein, B. (1983) Anal. Biochem. 132, 6-13

23 Verbeek, J. S., Roebroek, A. J. M., Van Den Ouweland, A. M. W., Bloemers, H. P. J. and Van De Ven, W. J. M. (1985) Mol. Cell. Biol. 5, 422-426

24 Verboomen, H., Wuytack, F., De Smedt, H., Himpens, B. and Casteels, R. (1992) Biochem. J. 286, 591-596

25 Papp, B., Enyedi, A., Kovács, T., Sarkadi, B., Wuytack, F., Thastrup, O., Gardos, G., Bredoux, R., Lévy-Tolédano, S. and Enouf, J. (1991) J. Biol. Chem. 266 14593-14596

26 Chirgwin, J. M., Przybla, A. E., MacDonald, R. J. and Rutter, W. J. (1979) Biochemistry 18, 5294-5299

27 Kievits, T., Dauwerse, J. G., Wiegant, J., Devilee, P., Breuning, M. H., Cornelisse, C. J., Van Ommen, G. and Pearson, P. L. (1990) Cytogenet. Cell Genet. 53, 134-136

28 Yunis, J. J., Sawyer, J. R. and Ball, D. W. (1978) Chromosoma 67, 293-307

29 Kozak, M. (1987) Nucleic Acids Res. 15, 8125-8148

30 Proudfoot, N. J. and Brownlee, G. G. (1976) Nature (London) 263, 211-214

31 Mitchinson, C., Wilderspin, A. F., Trinnaman, B. J. and Green, N. M. (1982) FEBS Lett. 146, 87-92

32 Ohta, T., Nagano, K. and Yoshida, M. (1986) Proc. Natl. Acad. Sci. U.S.A. 83, 2071-2075

33 Ovchinnikov, Y. A., Dzhandzugazyan, K. N., Lutsenko, S. V., Mustayev, A. A. and Modyanov, N. N. (1987) FEBS Lett. 217, 111-116
34 Lehrach, H., Drmanac, R., Hoheisel, J., Larin, Z., Lennon, G., Manaco, A. P.. Nizetic, D., Zehetner, G. and Poustka, A. (1990) in Genome Analysis: Genetic and Physical Mapping, vol. 1, pp. 39-81, Cold Spring Harbor Laboratory Press, Cold Spring Harbor, NY

35 Jackson, M. R., Nilsson, T. and Peterson, P. A. (1990) EMBO J. 9, 3153-3162

36 Foletti, D., Guerini, D. and Carafoli, E. (1995) FASEB J. 9, 670-680

37 Emeson, R. B., Hedjran, F., Yeakley, J. M., Guise, J. W. and Rosenfeld, M. G. (1989) Nature (London) 341, 76-80

38 McKeown, M. (1992) Annu. Rev. Cell Biol. 8, 133-155

39 MacLennan, D. H., Brandl, C. J., Champaneria, S., Holland, P. C., Powers, V. E. and Willard, H. F. (1987) Somat. Cell Mol. Genet. 13, 341-346

40 Callen, D. F., Baker, E., Lane, S., Nancarrow, J., Thompson, A., Whitmore, S. A., MacLennan, D. H., Berger, R., Cherif, D., Jarvela, I., Peltonen, L., Sutherland, G. R. and Gardiner, R. M. (1991) Am. J. Hum. Genet. 49, 1372-1377

41 Otsu, K., Fujii, J., Periasamy, M., Difilippantonio, M., Uppender, M., Ward, D. C. and MacLennan, D. H. (1993) Genomics 17, 507-509

42 Reiner, O., Carozzo, R., Shen, Y., Wehnert, M., Faustinella, F., Dobyns, W. B., Caskey, C. T. and Ledbetter, D. H. (1993) Nature (London) 364, 717-721

43 McDonald, J. D., Daneshvar, L., Willert, J. R., Matsumura, K., Waldman, F. and Cogen, P. H. (1994) Genomics 23, 229-232

44 Buchberg, A. M., Brownell, E., Nagata, S., Jenkins, N. A. and Copeland, N. G. (1989) Genetics 122, 153-161

Received 19 April 1996; accepted 13 May 1996 